\title{
Community-Society Equilibrium: Religious Organizations in the Service of a Secular State
}

\author{
Dikla Yogev ${ }^{1} \oplus$
}

Received: 24 December 2020 / Accepted: 23 August 2021 / Published online: 28 September 2021

(C) The Author(s), under exclusive licence to Springer Nature B.V. 2021

\begin{abstract}
Religious enclaves have a long history of relying on internal organizations to care for the vulnerable. Yet very occasionally they avail themselves of the services of those who are not community members. Police agencies working in these enclaves also often rely on community organizations to disseminate information, assist in maintaining public order, and increase police legitimacy. Using the framework of community-society and social control, this study identifies a shift of religious organizations toward greater integration into the public sphere. Under certain social conditions, religious organizations serve as agents of socialization for the enclave community and allow members of the community to participate in public actions, resulting inevitably in higher integration. This study suggests that the boundaries between community and society are flexible and may adjust under certain circumstances, even as religious constraints may pose obstacles for advancing community cooperation with such state organizations as the police.
\end{abstract}

Keywords Haredi organizations · Police legitimacy $\cdot$ Religious communities $\cdot$ Police and religion $\cdot$ Haredim $\cdot$ Israel $\cdot$ Zaka $\cdot$ Community-society

\section{Introduction}

There are relatively few studies that explore the relationship between religious enclaves and the state with respect to public services. A number of these focus on the charitable activities of faith-based organizations serving community members in the areas of education, social services, community policing, and crime prevention (Pegram et al. 2016; Manuel and Glatzer 2019), or on local institutions that care for the vulnerable (Cnaan and Heist 2018; Gray and Levitt 2020), often without the incentives of state funding and support. In terms of relations with the police, these organizations may also assist the police in maintaining the public order, either

Dikla Yogev

d.yogev@mail.utoronto.ca

1 University of Toronto, 14 Queen's Park Crescent West, Toronto, ON M5S 3K9, Canada 
directly or indirectly. The examination of Haredi (Ultra-Orthodox) organizations in Israel suggests that faith-based organizations may challenge the boundaries between the religious community and the broader society, playing a significant role in socializing members of the community by offering them opportunities to contribute to, integrate within, and be present in the public sphere. Although limited in capacity and reach, these two trends-inside out and outside in-inevitably reinforce each other and promote both greater integration of religious individuals into the secular sphere, and greater acceptance of religious practices outside the religious enclaves. Additionally, these organizations perform some share of policing actions, thus promoting police legitimacy and trust in and cooperation with the police.

Organizations that do this work of enabling integration between religious communities and the larger society tend to fall into a very specific framework: they serve both community and state without contradiction, finding neutral ground that allows the two sides to get to know one another without harm. Despite their function in allowing the two sides to get along, the organizations I am describing here are still identified by the secular public as highly religious Haredi organizations somewhat removed from Israeli life, while Haredim perceive these organizations as bordering on the secular, barely religious, and too Israeli. Thus, these organizations serve as a focal point of boundary negotiation for both the Haredim and the secular society in Israeli.

I argue that religious communities that have a flexible structure which allows limited communication with the outside, which might be called integrative enclaves (Sorek 2007), primarily serve the group interests to keep its structure alive. These enclaves, even in their exploration of dangerous practices that had previously been considered out of bounds, still serve the major directive of the group to keep its members compliant with its leaders. Therefore, new practices that find acceptance will be those that evince the least amount of contradiction with religious values and tradition, while also providing other benefits, for instance economic benefits (e.g., new practices of workforce participation that support large families), immediate contributions to physical well-being (e.g., medical organizations, road assistance, and public order), or technological advances that cannot be avoided (e.g., cellular phones and internet, which in the Haredi case are acceptable in their kosher variations). Another important trait of these integrative enclaves is the well-understood boundaries that separate them from outside actors. A Haredi organization that gradually evolves into an Israeli organization must not only specialize in matters that are internally acceptable for integration; it must also be legitimized by the state. Haredi organizations that serve the public challenge the predetermined boundaries dividing the Haredi community and Israeli society, thus inevitably serving as socialization agents for Haredi integration. However, the scarcity of Haredi organizations in the arena of criminal justice suggests that neither the community nor the state has come to terms with the potential for involving Haredi organizations in policing activities. 


\section{Religious Enclaves}

The extreme, intentional, and systematic segregation of the Haredi community is well theorized in the concept of the enclave introduced by the anthropologist Mary Douglas (1966, 2003). She argues that closed communities define themselves and create a sense of belonging for their members via their group positioning-as pure versus dirty, us versus them. Group members, as a result, make sense of their lives by choosing right from wrong. This symbolic system is reinforced through required garb, specific rituals, and prescribed behaviors, which provide meaning for group members and define their identity (Marsh and Jones 2018). Scholars of the Haredi community build upon Douglas's work by describing the Haredim as an enclave society (despite its relative size within the Israeli population) that distinguishes itself from the broader public in multiple ways, including dress and places of residence (Flint Ashery 2018). Almond et al. (2003) suggest that the Haredi enclaves emphasize the danger of being influenced by the secular culture, with religious leaders seeking to convince their followers that doing what the larger public does is wrong or dirty, while what the group does is both right and highly desirable. Indeed, to keep group identity alive and promote social control within the group, rabbinic authorities continuously exclude new varieties of food or activities, and introduce ever-more-stringent dress codes (Barack-Fishman 2007). This excluding mechanism, when successful, is governed by internal elites that seek to maintain their power within the community (Malach 2013).

Nevertheless, although various parts of the community present increasingly segregated behaviors, there is simultaneously a growing tendency toward openness to the larger public even among the most extreme Haredi sub-streams such as Toldot Aharon and Satmar (Keren-Kratz 2016). These changes are prevalent in education, employment (Hakak 2016), and cooperation with state agencies (Yogev 2021). Gapminimizing is effectively done through mechanisms that produce a more integrative enclave - a partial integration in different contexts and settings, which on the one hand allows the closed community to participate in activities that were previously off-limits, and on the other hand continues to keep the boundaries of the community sufficiently well defined (e.g., Sorek 2007 on Arab-Israelis, and Shavit and Wiesenbach 2012 on European-Muslim women). Integrative enclaves are described as those that facilitate community members' participation in permitted integrative activities while proscribing forbidden behaviors and activities. Along similar lines, Golan and Campbell (2015) studied major Haredi internet websites designed for the use of the Haredi community in accordance with rabbinic rules, tracing their growing popularity and engagement. Like Haredi newspapers that open the community to news and information, these websites in fact keep the boundaries and limits intact, as defined by religious rules and social norms. Haredi organizations seem to act in the same vein; however, they present interesting distinctive characteristics, especially as they grow and become established. 


\section{Faith-Based Organization and Collaboration with the State}

Most studies of religious organizations focus on the services provided to community members by local churches or small religious institutions (e.g., Evans and Hudson 2014; Campbell 2016; Cnaan and Heist 2018), or on the relationship between religion and state regulations among larger faith-based organizations, such as hospitals or social service agencies (e.g., Hosu and Frunză 2013; Berg 2015; Ivanova et al. 2019). Research suggests that in some cases these faith-based organizations evolve from achieving narrowly religious goals in the arenas of education and social services to establishing themselves as accepted professionals in a secular field, especially after government funding is obtained (Hosu and Frunză 2013; Sandu and Caras 2013; Nistor 2019). Studies show that when management and volunteers are affiliated with a specific faith-based community, the organization usually maintains its religious identity and commitment to promoting a religious agenda while serving clients (Bielefeld 2006; Crisp 2015). At the same time, these organizations can reach out beyond this religious affiliation professionally and administratively (Batley and Rose 2011; Sinha 2013), serving communities that are not directly affiliated with their specific religion or faith (Bielefeld and Cleveland 2013). A number of large Haredi organizations seem to have followed this pattern, broadening their reach beyond the community to serve the public even as their leadership remains completely Haredi. However, these organizations present some puzzling characteristics: only very few of them provide support to the police or the state; they generally are the first to serve the public in a specific area, doing so before receiving public funding (if they receive any at all); and the focus of their work is generally not on serving the vulnerable, but rather in the medical arena, for instance providing medical equipment to ailing individuals at low or no cost. There are, however, a few exceptions in the area of civil policing and public order. These characteristics suggest that Haredi organizations that are open to the public are not classic faith-based entities that focus on helping the vulnerable, in which growth brings dependency on public funding, but rather that these organizations, intentionally or not, have staked a place in Israeli society by specializing in useful, but not widely recognized, areas of public concern. ${ }^{1}$

\section{Community-Society and Civil Policing}

To better understand why Haredi organizations present an unusual profile, it is useful to look at theories of the boundaries of communities, especially Tönnies's distinction between Gemeinschaft and Gesellschaft (community/society). Developing Weber's ideas of community and economics (Weber 1978), Tönnies (Tönnies and Loomis 2002) views community institutions as those that focus on informal connections between family members and their immediate contacts. The community in

\footnotetext{
1 This article does not discuss Haredi Gemachim that are focused on Haredi recipients, and have no intentions to serve the public widely.
} 
this sense is based on traditional norms, strong social connections, and high solidarity among people; it may also be a religious group that shares the same values and has certain expectations for members' behavior (Ferguson et al. 2017). On the other hand, a society brings together individuals with a diverse variety of lifestyles, organized primarily through the small household, with a lack of strong emotional connections among unrelated individuals. Tönnies, who developed his ideas over a century ago (1887), argues that modern European society during the Industrial Revolution underwent a shift from a community structure to a society structure. This shift was accompanied by urbanization and the replacement of emotional connections by more business-like communication, in which financial interests are involved (Tjora and Scambler 2020). This transformation was accompanied, in the view of other scholars, by an anomie that reflects these dynamic and emerging social norms (Swader 2017). Studies that focus on neighborhood watch organizations suggest that forming a collaboration between police and civic policing organizations can increase police legitimacy and assist in public order issues, but also combat the anomie of modern society (Uhnoo and Hansen Löfstrand 2018; Fennelly et al. 2020). However, community members who volunteer for policing tasks (e.g., searching for missing persons) continue to reflect the shift from community to society-they assist the community but do so through institutional mechanisms (Sjösvärd 2014). Haredi organizations seem to fit this pattern: as they establish themselves, they present attributes that float in the gray area between community and society. Beyond this feature, shared with other hybrid organizations that move between the traditional and the modern, little is known about why Haredi organizations cluster around medical specializations, what role they play in Israeli society, why they present such consistent and distinctive behavior over time and across organizations, and why they are different from other faith-based organizations. This article thus aims to analyze several questions:

1. What accounts for the distinctiveness of Haredi organizations that also serve the public?

2. Why do most of them operate within the medical domain?

3. Why are they rarer in the civil policing and enforcement arena?

\section{The Haredi-Israeli Case}

Stadler (2012, pp. 141-144) explains the rise in Haredi non-profit organizations that serve the public as a cultural-religious shift from pure fundamentalism and separation from the state to a more flexible and accepting approach. According to Stadler, Haredi society has gradually been taking a more active part in Israeli civic society in Israel, as a result of constant pressure by a public resentful of such a large group drawing on state resources without contributing to the state. Consequently, the Haredim softened their fundamentalist approach, as evidenced by their serving the public through Haredi-run organizations, higher participation in the army and higher education, and so forth. Moreover, the tendency to serve society by opening their organizations to the public derives from religious values of voluntary care for 
others, which simultaneously revivifies civic values of citizenship, nationalism, and collectivity in the Israeli sphere (Stadler et al. 2008; Roos 2015). I argue that this evolution is rooted not only in redefined notions of Haredi citizenship, but-as with other faith-based organizations - also in the growth of Haredi organizations beyond the narrower religious community to a larger society that expects greater professionalism. Additionally, the term fundamentalism nowadays is considered highly divisive (as well as pejorative) and is far less frequently used to describe Haredi behavior than it was in the past. It is well understood that Haredim these days participate more in the workforce, with some enlisting in the army (albeit in small numbers) and seeking higher education (Zicherman and Cahaner 2012; Hakak 2016), although Haredi participation in the army and higher education was more prevalent in the British Mandate period and in the early years of the state of Israel. Nevertheless, the absence of Haredi organizations within the realm of social service and educational organizations that are not religious, and the flourishing of medical and lifesaving organizations, suggest that Haredi organizations are different from their peers among other religious communities in the forms taken by their service to the public. Their focus on emergency support and life-saving also illuminates the lack of such community-based alternatives in the secular arena, and emphasizes a gap in such services in the public Israeli space. The novelty of this Haredi organizational role in Israeli society also needs to be stressed: While it is true that historically the Haredi community in the diaspora (especially Europe and later in the British Mandate) created successful mechanisms for mutual aid as well as advocacy for important matters such as Sabbath practices and kashrut (Assaf and Bartal 1994; Wodziński 2005; Fisher 2016), this activity was more strongly focused on the internal needs of the community, without the dimension of caring for the needs of the surrounding nonJewish or non-Haredi society. The emerging phenomenon of Haredi organizations that reach out to the general population has no real historical precedent.

A major example is Zaka, a Haredi organization that deals with burial according to Jewish law. Zaka has evolved from a small volunteer-run organization that dealt strictly with preparing bodies of decedents (generally in terrorist attacks) for burial, into a complex organization that serves at an official capacity dealing with all sorts of emergencies, for example, in searches for missing persons, or as first responders in natural disasters. In its training, specializations, and level of command, Zaka resembles the police force and the army. The organization displays a unique style of collaboration with the police, where in some geographical areas Zaka employees wear the Israeli police uniform and are considered officers, for all intents and purposes (e.g., in accessing the internal Israel Police system, $R 7^{2}$ ). The phenomenon of Zaka is paralleled, although on a smaller scale, in the work of other organizations

\footnotetext{
${ }^{2}$ R7 denotes the source as Respondent 7. See more explanation below in the section on Study Design and the Appendix.
} 
that provide various services, mainly in emergency, medical, and related services ${ }^{3}$ : Ezer MiZion, ${ }^{4}$ Yad Sarah, ${ }^{5}$ and Yedidim. ${ }^{6}$

Within law enforcement, Zaka seems to be the sole player assisting the police in keeping public order and communicating with the police in community matters (reporting criminal activity, investigations, etc.). Interestingly, Zaka publicly announces that their services are offered to everyone, including non-Jews. In fact, a placard in the Zaka office in Bnei Brak proclaims: "You are in the right place-we cater to everyone! with no discrimination based on race or religion!". The placard shows a Haredi man and three angels-Arab, Christian, and Hasidic-Jewish. Yedidim, which deals with automotive emergencies, is less accepted in the mainstream Haredi world, and its structure seems more flexible than Zaka. For example, the first photo on its website ${ }^{7}$ shows a religious Jewish man and a secular woman, both dressed in uniform, fixing a car together. By contrast, Zaka does not allow women to serve in almost any capacity of its operations. These variations suggest that Haredi elites set the tone and direction for integration, and those organizations that conform more closely with their dictates will be more influential within Haredi culture.

\section{Critical Inquiry Using the Israeli Case Study}

The Haredi community comprises roughly twelve percent of the Israeli population (Choshen et al. 2017). Individuals in this community hold firm religious values and strongly oppose the secular lifestyle adopted by the majority of Israelis (Malchi and Ben-Porat 2018). The relationship between ethnic and religious identifications in the Haredi community offers the opportunity to explore the effect of religious practices and identity on police relations, because this group shares nationality and ethnicity with the majority secular group, in contrast to other minorities around the world that are usually distinct in both ethnicity and religion. Previous policing studies tend to highlight those factors that distinguish the smaller community from the larger one, such as studies on American Blacks that focus on racial factors as opposed to religious identity (Pegram et al. 2016). Studying the Haredi community in Israel (a majority Jewish state) eliminates the ethnic or racial difference, thus allowing a focus on the role that religion might play in policy.

More generally, the role of religion in policy is often omitted when investigating the relationship between minority groups and the criminal justice system (McFadyen and Prideaux 2014). Studies focusing on religion in that context are scarce, making

\footnotetext{
3 There are other Haredi organizations that show a similar pattern in areas that are less emergency-based response, for example, Pa'amonim (financial assistance) or Bat Melech (domestic violence help). However, these organizations can be viewed as those that intend to serve Haredim (similarly to Gemachim), target the Haredi population, and rarely serve those who are not.

4 A non-profit organization that helps in navigating medical problems.

5 A non-profit organization that helps in providing medical devices for free.

${ }^{6}$ A non-profit organization that assists with roadside emergencies as well as minor car repairs, for no charge.

7 https://yedidim-il.org/ (Hebrew).
} 
studies on Haredi community useful for filling in gaps in academic literature. The complicated and dynamic relationship this community holds with the police (Yogev 2010) makes this group similar to other minority groups (Ellison 2007; Huq et al. 2011). However, the channels of communication with the state that developed in the mid-1990s distinguish it from others in minority groups, further exemplifying the importance of conducting studies regarding the Haredi community and its relationship with the police.

As the Israeli society moves towards an increasingly right-wing Zionist ideology, so does the Haredi community, suggesting a potential explanation for the improvement in the relationship between the minority group and the state (Friedland and Moss 2015; Stadler et al. 2008). This positive trend is not fully understood, however, since it continues to grow even as conflicts between the secular government and the religious community persist (Burton 2015; Feraro, 2014).

\section{Study Design and Approach}

This study's goal is to illuminate the shared cultural views and structures that characterize the Haredi community. As such, an ethnographic approach (Hammersley 2007; Creswell 2008) was chosen and implemented via interviews, research reviews, media sources, and confidentially shared policy documents. The COVID-19 pandemic brought about the ability to collect real-time data regarding the actions of the Haredi community as the pandemic unfolded. Primarily relying on digital ethnography methods by observing day-to-day online activity of participants and in online communities (Hine 2017; Addeo et al. 2019), the data collected serve as an authentic fingerprint aiming to understand meanings and manifestations of everyday communication (Varis 2015; Pink 2016) between members and outsiders involved in the Haredi community via online platforms.

I used a snowball method to reach out and interview thirty informants in 2019. This method relies on prior connections, starting with personal connections and expanding to their acquaintances. An additional fifty-six people were later interviewed specifically about COVID-19 between March and November 2020. The coding system for the interviews shows the letter " $R$ " with a numeric order, for example: R59. More information about interviewees can be found in the appendix. Additionally, the communication application WhatsApp was used to reach participants, as this is a very popular app among the Haredi community (Klein and Urich 2014). The global pandemic brought a double-digit increase in Haredi WhatsApp users (R59, R63, R70), which allowed me to contact highly religious individuals who may not have otherwise been on social media. I joined several WhatsApp groups chats in the beginning of the outbreak, staying on top of communications sent and following up with participants regarding specific posts. This extraordinary access to informants vanished with time, and around September 2020 it was much harder to reach out to Haredi men and talk to them online. This could be explained by people beginning to go back to their everyday habits, and thus being less available for leisurely talks (Haredi women are almost entirely absent in the online groups). 
The study's participants are mostly men aged around 30-50 years of age. All those involved in the study are either directly from the Haredi community or are researchers, journalists, police officers, public service officers, religious leaders, or social activists responsible for or studying the Haredi population. Most of the informants preferred voice calls either via WhatsApp or via regular lines, for two main reasons. One concerns health and safety associated with COVID-19, but voice calls are also more acceptable than in-person meetings or video calls between a female researcher and Haredi men, within a strictly gender-segregated culture.

The method of conducting phone interviews has been described as fruitful, valid, reliable, and effective (Dimond et al. 2012; Hershberger and Kavanaugh 2017). Similar conclusions about data gathering and participant engagement are prevalent in this study as well. Further content analysis of the interview data collected, media received, and field observations was needed to reveal recurring themes. Data were analyzed by themes in a recursive process back and forth until the puzzle of information became coherent and clear (Stemler 2001; Creswell and David Creswell 2017).

\section{Findings}

This study sheds light on the various reasons and causes for the existence and expansion of large Haredi organizations, particularly arguing that these organizations play a specific role in negotiating the structural boundaries between community and society. More specifically, it seems that widely accepted organizations serve several goals, and I provide evidence for each to support my arguments.

Firstly, they provide an opportunity for Haredi men to take an active part in Israeli society outside military service, which remains controversial within the community. Volunteering in organizations such as Zaka or Yad Sarah regularly involves helping non-Haredi populations. Secondly, these organizations provide a clear framework for socially regulated volunteer work. As Haredi organizations, they obey religious rules (on Sabbath, regarding kashrut, gender segregation, etc.) that are not followed in non-Haredi organizations, which poses significant obstacles for Haredi volunteers. Thirdly, the structure of these organizations regulates the exposure of Haredi volunteers to secular culture, materials, or unacceptable settings, thus assisting the community (the rabbis, or rabbinic law) to maintain social control among community members. Fourthly, these organizations provide the community with activities, within clear boundaries, for youth who are considered rebellious because they lack the ability or will for continual Torah study all day; these organizations allow them to use the phone on the Sabbath, wear a uniform, wield a weapon, take part in the physical activities of policing or roadside assistance, and communicate with the nonHaredi population. Fifthly, Haredi organizations offer a compromise to the secular public that has been demanding greater Haredi contributions to the general society (especially the army and joining the workforce). Those organizations that are open to the public showcase that Haredim work for the common good, assisting the public in ways similar to military service or civil service. Nonetheless, these organizations reflect strong religious constraints in several respects. Their specialization seems to be dictated by the greater flexibility of religious rules in life-threatening situations. 
By contrast, religious rules prohibit reporting another Jew's misconduct to authorities, which makes cooperation in policing harder to enact within these boundaries.

Conversations with informants demonstrate that they see organizations as advocating for or representing the Haredi community among the general public, along with additional internal community functions (for example, providing activities for those who cannot study Torah all day). These organizations are viewed as highly professional, open to and providing the same service to the public of all faiths, and as entities that show the nice face of Haredim to the general public. These organizations are highly connected with and accepted within the Haredi community, their leadership is completely Haredi, and they are deeply involved in assisting the community with various needs (e.g., public order and medical assistance).

The astonishingly rapid development of Zaka and similar organizations requires an in-depth investigation as to why Haredim are interested in volunteering in these specific specializations, as the large number of volunteers is the engine that moves them-each organization has thousands of volunteers who are ready to respond at a moment's notice. Various explanations may shed light on this phenomenon: the Haredi community in general has internal social functions that replicate the state, and therefore the community is institutionally strong and highly established, especially in matters of internal enforcement (R73, R77, R80). For example, during COVID-19, Haredim in Jerusalem set up a small unofficial hospital that treated dozens of people in their homes without state regulation (R84). Haredi communities have emphasized internal help and charity, and these organizations are a natural development of older practices (R10, R11, R24, R25, R50). These organization also have the appeal of providing the excitement, fast-moving events, and heroic action that many seek in missing persons events, public order assistance, patrol policing, and other first-responder tasks, including work with dead bodies (R15, R31, R50). Others mentioned that the Haredi presence in community events allowed insiders some control, to keep the community safe (R12, R23). While these explanations for Haredi organizations focus on the strengths of the Haredi community, many respondents also discussed the controversial exemption of Haredim from army service, which made many of them uncomfortable: informants repeatedly argued that Haredi men suffer from a deep sense of inferiority in comparison with the manly image army service provides to secular men; some also spoke of their admiration for the army and their craving for a way to compensate for their lack of contribution in military service by volunteering in quasi-military Haredi organizations (R22, R23, R24, R25, R30, R42). In addition to healing this wound to Haredi masculinity, volunteering also helps the Haredi community fend off public criticism about their lack of military service, and convince the community internally that Zaka is a legitimate replacement for the army (R28, R30) that avoids entanglement in religious problems (R30, R84), and has the added benefit of showing that the Haredi way of life is capable of helping not only the community but also the public (R31, R32, R33, R37).

Zaka in particular focuses on fulfilling public needs both among the Haredim and across Israel. It is significant, then, that Zaka is perceived as an organization with a successful history of working with the state (R18, R52), of knowing how to cooperate professionally with the police without betraying the Haredi community (R18, R23, R25, R26, R31), of doing a job that no one wants to deal with (collecting dead 
bodies and remains) while also performing a valued religious deed (R53, R70, R72, R84), and of having a vast inventory of ready volunteers (R23). During the first wave of COVID-19, Zaka was among the few organizations that helped health officers disseminate information and regulations in Haredi neighborhoods (R82). Their action and access to uniforms and weapons fill a major role in the acquisition of prestige among Haredi men, who are respected beyond the community as official police volunteers (R31, R59, R70), even while they are careful to obey rabbinic rules, finding innovative halachic solutions where necessary (R7, R82). They also provide a better image for the police among the Haredim (R18). It is important to note that Zaka symbolizes the cultural shift the Haredi community is undergoing. Zaka volunteers are described as becoming Israeli (R84), professional and part of the nation (R30); you cannot run from being Israeli (R9). Some think that this perception derives from the significant changes over time of its founder, Yehuda Meshi Zahav, who evolved from being a religious radical of the sort identified with the neighborhood of Meah Shearim to becoming a vocal opponent of the irresponsible behaviors of many Haredim during COVID-19 (R67, R69, R70). He has also become more involved over time in secular-national matters, with his sons enlisting in the army, and himself promoting Zionism (R22, R34). (The recent evidence of his sexual misconduct and his suicide attempt is a subject for a different kind of research.)

A different perception seems to reign when informants discussed another Haredi organization-Yedidim (friends). Yedidim provides roadside assistance free of charge, helping thousands of people monthly (R34), and drawing volunteers from beyond the Haredi community. People refer to Yedidim as a marginal organization that deals with non-emergency situations (R31, R47), and do not consider it to be Haredi due to its secular volunteers (R80). Others referred to the significance of Yedidim as comparable to Zaka, and to some extent competing with Zaka's power and ability to serve in place of the police or other emergency bodies (R49, R51).

Zaka and Yedidim are not alone in serving as agents of socialization, with other organizations also helping to demonstrate the role that municipal and local government agencies can play in effecting change. In recent years, the state has culturally and halachically adapted its communication with Haredim, with local municipalities, academic programs, army programs, and local charities providing alternative channels for Haredim to integrate (R33, R34, R75, R84). In the specific arena of policing, a program for female Haredi investigators who are trained to work with Haredi women and children is considered to have been highly successful at building trust (R34, R53, R75, R86). Other successful programs have trained social workers and women's guides who work alongside the police in Beit Shemesh on issues such as school sexual abuse prevention (R35, R36, R42); police stations serving major Haredi populations often enlist only Haredi officers and maintain ongoing communication with local rabbis (R75, R82). The relative success of local governments and small organizations (e.g., Lo Tishtok [you shall not be silent], which deals with sexual abuse awareness) in actions like this are considered a direct result of urgent needs in the community that cannot be addressed by internal policing efforts, especially when sexual offenses are involved (R86).

It is illuminating to contrast these organizations that work at the boundaries between Haredi communities and the larger society with those that work strictly 
within the community, especially those which provide alternative and informal policing. Informants repeatedly mention the Shomrim (the keepers or the guards) and a modesty patrol (Heilman 1992; Inbari 2012) named Tohar Hamachane (community purity), organizations primarily active in internal community enforcement that operate within a legal gray zone and which rarely coordinate with the Israeli police. These organizations have diminishing power in present conditions, but in the past, some combined the goal of opposition to the secular state with the aim of enforcing religious dress codes, mainly on women in Jerusalem. Whereas Zaka is widely accepted among both the Haredim and the public and has significantly spread over a wider geographical arena, the Shomrim and Tohar lag behind, although both are still represented in many areas of Israel. Press coverage suggests that the Shomrim play a role somewhere between legal and illegal enforcement, using violence, ambushes, and other controversial practices to police the community, for instance, impersonating police to extract a confession from an alleged sex offender (Sternbach and Nachshoni 2016); Haredim often perceive them as worthless, Mosers [turncoats], Shabab, ${ }^{8}$ and vagrants (Cohen 2016).

Informants referred to the Shomrim as a dangerous organization that the police kept a watchful eye on in an attempt to limit their influence (R14, R17, R21, R31, R84), an organization seeking to evade police scrutiny, like unofficial emergency medical first-response organizations such as Hatzalah (R24, R62, R84). The Shomrim volunteers are considered intellectually inferior to others, unable to do much beyond following simple orders (R12, R21, R61). Informants provided detailed information about the methods by which the Shomrim enforce religious social control, specifically regarding modesty and sex offenses in insular Haredi neighborhoods: they beat people and follow them (R14, R53), doing internal enforcement beyond the scope of police invention (R34, R36, R47, R61) or punishing offenses people do not share with the police for fear that they will not respect religious sensitivities (R42, R51, R53). These organizations function according to the assumption that the community is invested in religious rules that are irrelevant in the Israeli sphere, such as modest attire and kosher phones (R60, R64, R84), and that some offenses are better kept under the radar, under rabbinical control (R57, R85) so that the Haredi community can maintain its respectable image and protect family reputations (R47, R51, R86).

Although Zaka and certain Haredi policing programs enjoy legitimacy among the Haredim, the Israeli public, and the police, religion perhaps continues to pose a challenge to the ability of these organizations to exist at the intersection of the secular and Haredi Israeli worlds. Informants referred to Yehuda Meshi Zahav and his controversial personality, as someone who confused Haredim when he began to express political, pro-Zionist views (R42), when his sons enlisted in the army and, shunning traditional matchmaking, married women of their choice (R51, R53), and when Zaka failed to adhere with complete stringency to religious rules (R18, R24). Some also discussed the threat to Haredi collective power that Israelism entailed; in this view, Haredim were experiencing a collective dilemma, in their official hatred

\footnotetext{
8 Problematic or militant youth, from the Arab word "Shabab" [youth].
} 
for a state that also benefitted them, in which official Haredi opposition continues to be required even as the feelings behind this rejection of the state continue to grow weaker over time (R67, R70, R73, R86).

\section{Discussion}

Common ground is the power that connects a religious community with the secular majority. Despite significant differences in world views, Haredi organizations are visible features of the larger Israeli culture. The features that unite organizations that have evolved from the private Haredi sphere to the public Israeli sphere include their operation in relatively neutral areas, from the secular point of view (i.e. providing medical devices, collecting remains of disaster victims), while simultaneously doing high-status work from a religious point of view-deeds that are considered supreme acts of charity. In the case of Zaka, it is clear that on the one hand they serve the public and also do a job that no one else is interested in doing, and on the other hand they fulfill a good deed that is required by religious law. Other examples are mostly found in the medical arena (Yad Sarah, Ezer Mizion), and the same explanation applies to them. They provide medical help, doing charity on the highest level (Roos 2015), and at the same time refrain from entering into risky religious territory in their collaboration with the state. In this respect, Haredi organizations participate in the making of the integrative enclave with the state and the Israeli society.

By contrast, the absence of genuine collaboration between the state and the police and the non-state Haredi enforcement and policing organizations, on such matters as domestic violence, sexual abuse, and other less severe offenses, clarifies the boundaries of this religious culture. Traditional Jewish texts and culture abhor the Moserthe turncoat who reports on fellow Jews or collaborates with external authorities, as a significant violator of religious law; therefore, the appetite to develop collaborations with the police is non-existent. Community organizations that deal internally with severe infractions (mainly sexual abuse and domestic violence) thus operate under the radar and perform their work away from the public eye, using questionable and sometimes violent methods. This type of organization, it is fair to say, cannot pave a clear path for collaborative work with the police on internal matter enforcement, even where common interests-warning offenders and preventing crimemay exist. If Haredim are not eager to work with the police in such matters, the police are similarly not enthusiastic about cooperating with organizations with a reputation for violence. The beliefs about the Moser, and the presence of non-police enforcement organizations, may also put police legitimacy in jeopardy among community members who may want to cooperate or report crime.

Nevertheless, modernizing forces are affecting this area as well. Given that being Israeli is becoming more and more acceptable among the Haredim, the opportunity to join forces with the state does not seem impossible anymore. Thus, organizations like Zaka that obey rabbinical laws while benefiting the state in their work aid in the evolutionary process of a more-Israeli Haredism, and in this way offer more than care for dead bodies. Zaka, for example, has occasionally joined forces with the police in Bnei Brak in joint police-community operations. Although this 
collaboration is limited in scope and de facto not all actions are reported to the police chain of command, it still signifies the possibility of more sustained cooperation.

Tönnies's model of community/society (Gemeinschaft/Gesellschaft) (Tönnies and Loomis 2002; Tjora and Scambler 2020) provides a window into a society in which Gemeinschaft and Gesellschaft exist simultaneously, even as the smaller and more traditional community continues to rapidly modernize and more closely resemble the more urbanized (post-)industrial society within which it lives. New organizations such as Yedidim (roadside assistance), which may derive from traditional mutual aid circles, are more inclusive than their precursors in both their membership and their activities, and are somewhat detached from the traditional repertoire of religious deeds (beyond doing good). Similarly, Lo Tishktok (you shall not be silent) started as a Haredi organization, but quite quickly became popular among the public and is now led and administered by a team that is not Haredi. Older organizations such as Zaka, which is completely run by Haredi leadership and volunteers, maintain traditional gender segregation but show a strong tendency to operate on behalf of both the community and the society. Along similar lines, although with many non-Haredi volunteers, Yad Sarah and Ezer Mizion, two large medical organizations, are led by a Haredi team but serve the public. In this way, these organizations challenge social norms, mediate communication within society (Roos et al. 2015), facilitate integration into the government and the public elite, and create a path for Haredi acceptance in the public Israeli society. In some, as can be seen in Yedidim or Yad Sarah, integration is already happening between sub-communities, and nonHaredim also serve and take part in the organization.

To summarize, religious organizations serve as major actors in the dynamic negotiations between Haredim, the state, and the secular sphere, mediating between the Haredi community and the state through their actions. They redefine the boundaries between community and society, changing the perceptions of Haredim toward the larger society, which is seen by both sociologists and Haredim as a not entirely appealing sphere in which the interests of the individual and the forces of the marketplace reign supreme. In their hybrid, blurry, and ambiguous character between community and society, Haredi organizations allow both sides to explore different worlds and get to know one another, while avoiding explosive disagreements. Their ambiguity is significant: these organizations are seen as Haredi to the secular eye, but are recognized as less religious from the Haredi perspective; they offer volunteer opportunities, including some that provide Haredi men a feeling of being almost in the army, and a sense of contribution to the society, although secular Israelis are far from recognizing this volunteer work as equivalent to army service; and they serve the public without a clear monetary incentive while obeying religious rules such as the prevention of autopsies and gender segregation.

Nevertheless, the scarcity of organizations devoted to criminal justice signals that the necessary conditions for police-organization cooperation have not been fully met. Relevant issues are either perceived as internal community matters, in which the state has no vested interest (e.g., modesty patrols), or as too sensitive for public airing (e.g., cases of sexual abuse). Successful cooperation with the state, as exemplified by Zaka, shows that police-community cooperation depends on this cooperation being both highly respected and perceived as completely harmless by 
the community, while also being almost insignificant to the state (e.g., preventing autopsies). Another option for successful cooperation presents itself in situations in which the community is unable on its own to solve deeply pressing issues such as sex offenses, so that members of the community eventually approach the police and accept culturally accommodated help.

The study presents several limitations. First, the study focuses on police-community actions, and does not include any of the massive data on other types of Haredi organizations that collaborate with the state. Findings should be interpreted cautiously when generalizing to other government agencies. Second, care must be taken when interpreting the results of the study not to generalize to diaspora Haredi communities or other religious communities. The present study focuses on the Haredi community in Israel, which is shaped by a much different context than Haredi Jews living in the diaspora. Third, this study focused on the unique relationship that the Haredi community developed with police in the state of Israel. Each minority community around the globe experiences its own challenges in respect to modernization and religious practices, and thus develops its own unique mechanisms and communication channels, leading to unique relationships with the criminal justice system. Lastly, this study opens up the question of whether developments within the Haredi community in Israel might have ramifications for the question of the Israeli Arab minority, which has been experiencing a growing crime and homicide rate in recent years. This is despite the fact that more young Israeli Arabs in Israel participate in civil service and are more integrated in the public arena of work and higher education. Future research is needed to study the similarities and differences in these two communities of lifesaving as well as community policing organizations in collaboration with the state, and their potential in promoting state legitimacy and trust.

\section{Appendix}

\section{Interviews (most of the interviews were conducted by phone during 2019 and 2020)}

- R1, R4, R5, R7, R10, R11, R13, R15, R17, R23, R24, R25, R26, R31, R48, R50, R53, R61, R62, R71, R72, R74, R75, R82- Haredi police officer / police officer with Haredi population responsibility (some are former officers)

- R2, R3, R8, R12, R14, R16, R18, R19, R20, R27, R28, R29, R30, R32, R34, R35, R37, R38, R39, R40, R42, R43, R44, R45, R46, R52, R54, R55, R56, R58, R59, R65, R76, R77, R83, R84- journalist / researcher / government policy official (Haredi population speciality)

- $\quad$ R36, R41, R47, R49, R51, R57, R60, R67, R68, R69, R73, R78, R80, R85, R86social activists / community broker / religious leaders

- R6, R9, R21, R22, R33, R63, R64, R66, R70, R79, R81- anonymous 
Funding Travel funding was received for this study.

\section{Declarations}

Conflict of interest The author has no conflict of interest.

Human and animal rights This article contains an approved study with human participants performed by the author.

\section{References}

Addeo, Felice, A. Delli Paoli, Maria Esposito, and M. YleniaBolcato. 2019. Doing social research on online communities: The benefits of netnography. Athens Journal of Social Sciences 7(1): 9-38.

Almond Gabriel A., R. Scott Appleby, and Emmanuel Sivan. 2003. Strong Religion, The Rise of Fundamentalism around the World. Chicago: University of Chicago Press.

Assaf David and Bartal, Israel. 1994. Intercession and Orthodoxy: Poland's Tsadikim in new times. In Rachel Elior, Israel Bartal, Chone Shmeruk (eds.), Tsadikim: Research on Poland's Hasidism, 65-90. Jerusalem: Mosad Bialik [Hebrew].

Batley, Richard, and Pauline Rose. 2011. Analysing collaboration between non-governmental service providers and governments. Public Administration and Development 31(4): 230-239.

Berg, Thomas C. 2015. Religious accommodation and the welfare state. Harvard Journal of Law \& Gender 38(2015): 103.

Bielefeld, Wolfgang. 2006. Investigating the implementation of charitable choice. Journal of Religion \& Spirituality in Social Work: Social Thought 25 (3-4): 151-173.

Bielefeld, Wolfgang, and William Suhs Cleveland. 2013. Defining faith-based organizations and understanding them through research. Nonprofit and Voluntary Sector Quarterly 42(3): 442-467.

Burton, Elise K. 2015. An assimilating majority?: Israeli marriage law and identity in the Jewish state. Journal of Jewish Identities 8(1): 73-94.

Campbell, David. 2016. Small faith-related organizations as partners in local social service networks. Religions 7(5): 57.

Choshen, Maya, Malach, Gilad. and Cahaner, Lee. 2017. The yearbook of Ultra-Orthodox society in Israel 2017. Jerusalem: Israel Democracy Institute, Jerusalem Institue for Policy Research. [Hebrew].

Cnaan, Ram A., and H. Daniel Heist. 2018. Religious congregations as community hubs and sources of social bonding. Handbook of community movements and local organizations in the 21st century. Springer, Cham. 391-403.

Cohen, Yisrael. 2016. Hashomrim saw a Haredi man beats his wife and were silent. Kikar Hashabat. June 19th, 2016. Talkbacks to https://www.kikar.co.il/abroad/201804.html

Creswell, John W. 2008. Research design: Qualitative, quantitative, and mixed methods approaches, 3rd ed. Thousand Oaks, CA: Sage Publications.

Creswell, John W., and J. David Creswell. 2017. Research design: Qualitative, quantitative, and mixed methods approaches. Sage Publications.

Crisp, Beth R. 2015. Challenges to organizational spirituality as a consequence of state funding. Journal for the Study of Spirituality 5(1): 47-59.

Dimond, Jill P., Casey Fiesler, Betsy DiSalvo, Jon Pelc, and Amy S. Bruckman. 2012. Qualitative data collection technologies: A comparison of instant messaging, email, and phone. In Proceedings of the 17th ACM international conference on Supporting group work, pp. 277-280.

Douglas, Mary. 1996, 2003. Purity and danger: An analysis of concepts of pollution and taboo. Routledge.

Ellison, Graham. 2007. A blueprint for democratic policing anywhere in the world? Police reform, political transition, and conflict resolution in Northern Ireland. Police Quarterly 10(3): 243-269.

Evans, Kiameesha R., and Shawna V. Hudson. 2014. Engaging the community to improve nutrition and physical activity among houses of worship. Preventing Chronic Disease 11.

Fennelly, Lawrence J., Marianna A. Perry, and Michael J. Fagel. 2020. Encompassing effective crime prevention solutions in 2020 and beyond: concepts and strategies. In Handbook of loss prevention and crime prevention, pp. 85-97. Butterworth-Heinemann. 
Feraro, Shai. 2014. Two steps forward, one step back: The shaping of a community-building discourse among Israeli pagans. Israel Studies Review 29(2): 57-77.

Ferguson, Todd W., Samuel Stroope, Joshua C. Tom, Brita Andercheck, and Brandon C. Martinez. 2017. Social sources of community solidarity in US congregations. Sociological Spectrum 37(4): 223-236.

Fisher, Netanel. 2016. The fundamentalist dilemma: Lessons from the Israeli Haredi case. International Journal of Middle East Studies 48(3): 531-549.

Flint Ashery, Shlomit. 2018. Schelling-type micro-segregation in a Hassidic enclave of Stamford-Hill. Housing Studies 33(7): 1038-1059.

Friedland, Roger, and Kenneth B. Moss. 2016. Thinking through religious nationalism. Words, pp. 419462. Fordham University Press.

Golan, Oren, and Heidi A. Campbell. 2015. Strategic management of religious websites: The case of Israel's orthodox communities. Journal of Computer-Mediated Communication 20(4): 467-486.

Gray, Breda, and Peggy Levitt. 2020. Social welfare versus transnational social protection regimes: the changing roles of church and state. Journal of Ethnic and Migration Studies: 1-19.

Hakak, Yohai. 2016. Haredi masculinities between the yeshiva, the army, work and politics: The sage, the warrior and the entrepreneur. Brill.

Hammersley, Martyn. 2007. Ethnography. In George Ritzer (Ed.). The Blackwell encyclopedia of sociology. Malden, MA: Wiley-Blackwell.

Heilman, Samuel C. 1992. Defenders of the faith: Inside Haredi Jewry. University of California Press.

Hershberger, Patricia E., and Karen Kavanaugh. 2017. Comparing appropriateness and equivalence of email interviews to phone interviews in qualitative research on reproductive decisions. Applied Nursing Research 37: 50-54.

Hine, Christine. 2017. From virtual ethnography to the embedded, embodied, everyday internet. In Hjorth, Larissa, Heather Horst, Anne Galloway, and Genevieve Bell, eds. The Routledge companion to digital ethnography. Taylor \& Francis, pp. 47-54. Routledge.

Hosu, Ioan, and Sandu Frunză. 2013. Religious affiliation and social action in the public space. Revista De Cercetare Şi Intervenţie Socială 43: 240-254.

Huq, Aziz Z., Tom R. Tyler, and Stephen J. Schulhofer. 2011. Mechanisms for eliciting cooperation in counterterrorism policing: Evidence from the United Kingdom. Journal of Empirical Legal Studies 8(4): 728-761.

Inbari, Motti. 2012. The modesty campaigns of Rabbi Amram Blau and the Neturei Karta movement, 1938-1974. Israel Studies 17(1): 105-129.

Ivanova, Olga S., Irina S. Chalykh, Boris V. Makogon, Leonid P. Rasskazov, and Elvira M. Vasekina. 2019. Investigation the role of religious organizations in system of general education: Forms of state-confessional interaction. Humanities \& Social Sciences Reviews 4: 818-821.

Keren-Kratz, Menachem. 2016. Westernization and Israelization within Israel's extreme Orthodox Haredi society. Israel Studies Review 31(2): 101-129.

Klein, Tzvika and Urich, Yonatan. 2014. Haredi WhatsApp groups: Porno and gossip [Hebrew]. NRG Jan 20th, 2014. https://www.makorrishon.co.il/nrg/online/11/ART2/542/145.html

Malach, Gilad. 2013. New consociationalism: Public policy strategy towards the Ultra-Orthodox society. Dissertation. Jerusalem: The Hebrew University of Jerusalem. [Hebrew].

Malchi, Asaf, and Guy Ben-Porat. 2018. Home and away: Volunteering among Ultra-Orthodox men in Israel. International Journal of Sociology and Social Policy 38(5-6): 411-425.

Manuel, Paul Christopher, and Miguel Glatzer, eds. 2019. Faith-based organizations and social welfare: Associational life and religion in contemporary Western Europe. Cham, Switzerland: Palgrave Macmillan.

Marsh, Ben, and Janet Jones. 2018. Reading social symbols systems. In Ram A. Cnaan and Carl Milofsky (eds), Handbook of Community Movements and Local Organizations in the 21st Century, 61-77. Cham: Springer.

McFadyen, Alistair, and Melanie Prideaux. 2014. The placing of religion in policing and policing studies. Policing and Society 24(5): 602-619.

Nistor, Polixenia. 2019. Social services offered by faith-based organizations in the post-secular society. Postmodern Openings 10(4): 65-103.

Pegram, Kashea, Rod K. Brunson, and Anthony A. Braga. 2016. The doors of the church are now open: Black clergy, collective efficacy, and neighborhood violence. City \& Community 15(3): 289-314.

Pink, Sarah. 2016. Digital ethnography. Innovative methods in media and communication research: $161-165$. 
Roos, Lena. 2015. If I am only for myself, who am I? In L. Hustinx, J. von Essen, J. Haers, and S. Mels (eds), Religion and volunteering. Nonprofit and civil society studies, 41-57. Cham: Springer.

Roos, Patrick, Michele Gelfand, Dana Nau, and Janetta Lun. 2015. Societal threat and cultural variation in the strength of social norms: An evolutionary basis. Organizational Behavior and Human Decision Processes 129: 14-23.

Sandu, Antonio, and Ana Caras. 2013. Deconstruction of charity: Postmodern ethical approaches. Journal for the Study of Religions and Ideologies 12(36): 72-99.

Shavit, Uriya, and Frederic Wiesenbach. 2012. An integrating enclave: The case of Al-Hayat, Germany's first Islamic fitness center for women in Cologne. Journal of Muslim Minority Affairs 32(1): 47-61.

Sinha, Jill Witmer. 2013. Unintended consequence of the faith-based initiative: Organizational practices and religious identity within faith-based human service organizations. Nonprofit and Voluntary Sector Quarterly 42(3): 563-583.

Sjösvärd, Alf. 2014. Fallet Missing People Sweden: Gemeinschaft och Gesellschaft $i$ en frivillig sökarorganisation. Master thesis in Criminology [Swedish].

Sorek, Tamir. 2007. Arab soccer in a Jewish state: The integrative enclave. Cambridge: Cambridge University Press.

Stadler, Nurit. 2012. A well-worn tallis for a new ceremony: trends in Israeli Haredi culture. Academic Studies.

Stadler, Nurit, Edna Lomsky-Feder, and Eyal Ben-Ari. 2008. Fundamentalism's encounters with citizenship: The Haredim in Israel. Citizenship Studies 12(3): 215-231.

Stemler, Steve. 2001. An overview of content analysis. Practical Assessment, Research \& Evaluation 7(17): 137-146.

Sternbach, Ariela and Nachshoni, Kobi. 2016. Watch: Hashomrim force a Haredi man to plead guilty for sex offences [Hebrew]. YNET June 5th, 2016. https://www.ynet.co.il/articles/0,7340,L-4812264,00. html

Swader, Christopher S. 2017. Modernization, formal social control, and anomie: A 45-society multilevel analysis. International Journal of Comparative Sociology 58(6): 494-514.

Tjora, Aksel and Graham Scambler. 2020. Community as solidarity. In: Tjora, Aksel, and Graham Scambler (eds.) Communal forms: A sociological exploration of concepts of community, 9-22. London: Routledge.

Tönnies, Ferdinand, and Charles Price Loomis. 2002. Community and society. Mineola, NY: Dover.

Uhnoo, Sara, and Cecilia Hansen Löfstrand. 2018. Voluntary policing in Sweden: Media reports of contemporary forms of police-citizen partnerships. Journal of Scandinavian Studies in Criminology and Crime Prevention 19(1): 41-60.

Varis, Piia. 2015. Digital ethnography. In: Georgakopoulou, Alexandra, and Tereza Spilioti (eds.). The Routledge handbook of language and digital communication, 55-68. London: Routledge.

Weber, Max. [1922] 1978. Economy and society. Berkeley: University of California Press.

Wodziński, Marcin. 2005. Hasidism, Shtadlanut, and Jewish politics in nineteenth-century Poland: The case of Isaac of Warka. The Jewish Quarterly Review 95(2): 290-320.

Yogev, Dikla. 2010. Public attitudes towards the Israeli police 2010. Tel Aviv, Israel: State of Israel, Ministry of Public Security (Hebrew).

Yogev, Dikla. 2021. Social capital transformation and social control: What can we learn from the changing style in communication between religious communities and the police during COVID-19. Policing and Society. https://doi.org/10.1080/10439463.2021.1965141.

Zicherman, Haim. \& Cahaner, Lee. 2012. Modern Ultra-Orthodoxy: The emerging Haredi middle class in Israel. Jerusalem, Israel: Israel Democracy Institute (Hebrew).

Publisher's Note Springer Nature remains neutral with regard to jurisdictional claims in published maps and institutional affiliations.

Dikla Yogev received her MA in Sociology at Tel-Aviv University and is a PhD candidate at the Centre for Criminology and Sociological Studies, University of Toronto, where she has also taught undergraduate courses in Israel Studies and Social Control. She serves as research manager for Dr. Naomi Seidman's "Bais Yaakov Project"; and has recently published in Policing and Society. 